\title{
Technology, Taphonomy, and Seasonality: Understanding Differences between Dorset and Thule Subsistence Strategies at Iqaluktuuq, Victoria Island
}

\author{
Lesley Howse ${ }^{1}$ and T. Max Friesen ${ }^{2}$
}

(Received 19 February 2016; accepted in revised form 13 July 2016)

\begin{abstract}
This paper examines differences between Late Dorset and Thule Inuit subsistence economies at the Bell site on Victoria Island, Nunavut. This location is relatively unusual in the Canadian Arctic because local subsistence was based largely on caribou and fish, rather than the sea mammals that dominate in most other regions. For both periods, animal bone samples are quantified in terms of taxonomic frequencies, element (body part) distributions, seasonality, prey demography, and bone modifications such as cutting, burning, and gnawing. A comparison between the periods indicates many broad similarities in subsistence, but some subtle differences suggest that the Thule had a more focal and specialized economy, with a slightly different seasonal profile.
\end{abstract}

Key words: Dorset; Thule; hunting technologies; taphonomy; subsistence economies; seasonality; zooarchaeology

RÉSUMÉ. Le présent article porte sur les différences entre l'économie de subsistance du Dorsétien récent et l'économie de subsistance des Inuits thuléens au site Bell de l'île Victoria, au Nunavut. Cet emplacement de l'Arctique canadien est assez inhabituel en ce sens que la subsistance de la région reposait grandement sur le caribou et le poisson, et non pas sur les mammifères marins qui dominent la plupart des autres régions. Pour ces deux périodes, les échantillons d'ossements d'animaux sont quantifiés en fonction des fréquences taxonomiques, de la répartition des éléments (restes), de leur saisonnalité, de la démographie des proies et des altérations subies par les os, comme les marques de coupure, de brûlure et de rongement. La comparaison des périodes permet de remarquer de nombreuses similitudes générales sur le plan de la subsistance, mais certaines différences subtiles suggèrent que les Thuléens avaient une économie plus concentrée et spécialisée de même qu'un profil saisonnier légèrement différent.

Mots clés : Dorset; Thulé; technologies de chasse; taphonomie; économies de subsistance; saisonnalité; zooarchéologie

Traduit pour la revue Arctic par Nicole Giguère.

\section{INTRODUCTION}

The culture history of the eastern Arctic is made up of two quite different traditions. The earlier Paleo-Inuit (PaleoEskimo) immigrants arrived from the west around $3000 \mathrm{cal}$ $\mathrm{BCE}$ and lived in the east until roughly $1300 \mathrm{cal} \mathrm{CE}$. Their final expression is known as Late Dorset. The more recent Thule Inuit arrived as a separate wave of immigration from Alaska, probably during the 13th century CE. These two societies, Late Dorset and Thule Inuit, were alike in many ways; both were technologically advanced huntergatherer societies, subsisting on most of the same limited range of available Arctic species and subject to the same severe environmental constraints. However, there were also significant contrasts between the two traditions, including a number of critical technological differences, as well as many aspects of social organization and perhaps worldview (Maxwell, 1985).
Many authors have linked these differences between Late Dorset and Thule, at least in a general sense, to their potential for differential economic success (e.g., Bielawski, 1979; Maxwell, 1985; McGhee, 1996; Friesen, 2000). Most particularly, several categories of Thule technology are seen as having delivered significant advantages for acquiring and transporting food. For example, Thule harpoon float technology allowed greater success rates in open water and ice edge hunting; Thule whaling technology allowed acquisition of bowhead whales, which in many regions could represent a focal resource; Thule bows and arrows were more efficient than Dorset lances in acquiring terrestrial mammals; Thule had more diverse fishing technologies, including hooks, as well as specialized bird spears; and finally, Thule had dogsleds and umiaks capable of transporting greater volumes of material than comparable Dorset technologies (Knuth, 1952; McCartney, 1979; Morrison, 1983; Maxwell, 1985; Whitridge, 2001; McGhee, 2005; Park, 2010; Friesen, 2013).

\footnotetext{
${ }^{1}$ Corresponding author: Department of Anthropology, McGill University, 855 Sherbrooke Street West, Montreal, Quebec H3A 2T7, Canada; lesley.howse@mcgill.ca

${ }^{2}$ Department of Anthropology, University of Toronto, 19 Russell Street, Toronto, Ontario M5S 2S2, Canada

(C) The Arctic Institute of North America
} 
Understanding the impacts of these many differences is central to one of the critical questions in Arctic archaeology: how did Thule Inuit replace Dorset PaleoInuit so rapidly and completely? While a number of factors were likely at play, central to many explanations is the idea that Thule technology allowed them to acquire a greater volume of resources, more reliably, than their Dorset predecessors could. In essence, the argument is that their subsistence economy gave the Thule Inuit a competitive advantage which, when coupled with social factors such as notions of territoriality and experience with interregional conflict, allowed Thule to displace Dorset rapidly across the Canadian Arctic and Greenland.

A logical way to evaluate the potential differences in economies and how they relate to the Dorset-Thule succession is to compare faunal samples from Late Dorset and Thule assemblages close to one another in space and time. How similar or different are they? And do they differ in ways that can be linked directly to the known technological differences between the two societies? Surprisingly, only two formal studies of this type have been performed: one is a detailed comparison of Late Dorset and Thule faunal assemblages from Cape Grinnell in Greenland (Darwent and Foin, 2010), and the other, a multiregional study centred on a formal evaluation of the role of technology in observed faunal differences (Howse, 2016).

In this paper, we focus on one of the regions included in the multiregional study conducted by Howse (2016) and compare the fauna from Late Dorset and Thule contexts at the Bell Site, located in the Iqaluktuuq region of southeastern Victoria Island, Nunavut. Though the radiocarbon dates from these contexts indicate a significant time gap between the occupations at the site (Table 1), there is no clear indication that available resources differed between the Late Dorset and Thule Inuit occupations, which suggests that the samples are comparable. This region is noteworthy as a relatively unusual context (by Arctic standards) in which seals were rare and large marine mammals were not available, but caribou and anadromous Arctic char were abundant. We contrast the frequencies of different taxa, body parts, bone modifications, and other phenomena of the two samples in order to begin to come to grips with just how similar, or different, the economies of the two societies were.

\section{BACKGROUND: THE IQALUKTUUQ REGION}

Iqaluktuuq, which means 'place of many char,' is located on the southeastern coast of Victoria Island $60 \mathrm{~km}$ northwest of Cambridge Bay (Fig. 1). The region includes the land on both sides of the Ekalluk River along a $3 \mathrm{~km}$ stretch connecting Ferguson Lake to Wellington Bay on the Arctic Ocean. Iqaluktuuq is characterized by a Low Arctic climate, and the current landscape consists mainly of exposed cobble beach ridges and vegetated areas dominated by sedges, grasses, and lichens (Porinchu et al., 2009).
Marine mammals are relatively infrequent in Wellington Bay, and historically Inuit have favoured the Cambridge Bay area for hunting seals (Taylor, 1972). Ringed seals (Pusa hispida) and bearded seals (Erignathus barbatus) inhabit Wellington Bay (Riewe, 1992), where they can reside year-round because of their ability to maintain breathing holes. However, larger marine mammals, including walrus (Odobenus rosmarus) and whales (bowhead, Balaena mysticetus and beluga, Delphinapterus leucas) are either completely absent or so rare that they have never been a significant part of any local economy (Banfield, 1974). Polar bears (Ursus maritimus) are likewise extremely rare.

The short list of terrestrial mammals is dominated by caribou. The caribou in the Iqaluktuuq region today are part of the Dolphin and Union herd (Rangifer tarandus groenlandicus), though the smaller Peary caribou ( $R$. $t$. pearyi) are found in the northwestern part of the Island (Gunn and Fournier, 1996; COSEWIC, 2004). The Dolphin and Union herd migrates through Iqaluktuuq twice a year, with particularly concentrated movements during the critical fall migration (Jakimchuk and Carruthers, 1980). As many as 100000 caribou are estimated to have summered on Victoria Island prior to the $1920 \mathrm{~s}$, when the population crashed (Manning, 1960). A second large herbivore often available on Victoria Island is the muskox (Ovibos moschatus) (Dumond, 2006). Muskoxen occur as individuals or in small herds (usually numbering 2-34 individuals), and they do not migrate over significant distances (Jingfors, 1984). Additional terrestrial resources include wolf (Canis lupus), Arctic fox (Vulpes lagopus), Arctic hare (Lepus arcticus), and wolverine (Gulo gulo). Small mammals include Arctic ground squirrels (Spermophilus parryii), lemmings (Dicrostonyx sp.), and ermine (Mustela erminea). Grizzly bears (Ursus arctos) are now frequent visitors; however, their frequency in the past is unknown.

The Ekalluk River supports a large population of Arctic char (Salvelinus alpinus). Although a downstream run occurs in the spring, the most important run occurs in late August, when the fish return from the ocean to the freshwater ecosystem (DFO, 2004). Lake trout (Salvelinus namaycush) are present year-round in lakes and streams (Pielou, 1994), and whitefish (Coregonus clupeaformis) and sculpin (Cottidae sp.), while not as abundant, are also occasionally available (e.g., Norman and Friesen, 2010).

Several species of geese (e.g., Canada Goose, Branta canadensis, Snow Goose, Chen caerulescens), ducks (e.g., Common Eider, Somateria mollissima, King Eider, Somateria spectabilis, Long-tailed Duck, Clangula hyemalis), and gulls (e.g., Glaucous Gull, Larus hyperboreus, Thayer's Gull, Larus thayeri) visit the region between June and August (Parmalee et al., 1967). Other avian visitors include Sandhill Cranes (Grus canadensis), Arctic Loons (Gavia arctica), and various jaeger species (Stercorarius sp.). Year-round residents include Common Ravens (Corvus corax), and both Willow (Lagopus 
TABLE 1. Radiocarbon dates on caribou bone from the Bell site. S-3038 is a conventional date; all others are accelerator mass spectrometry (AMS) dates.

\begin{tabular}{llll}
\hline \hline Feature & Lab no. & Radiocarbon age BP & Calibrated age ranges CE, 1 sigma \\
\hline House 6 & S-3038 & $1035 \pm 125 \mathrm{BP}$ & $882-1158$ \\
H6 midden & UCIAMS 76632 & $940 \pm 15 \mathrm{BP}$ & $1038-1049,1084-1124,1136-1150$ \\
TP4 & UCIAMS 106725 & $810 \pm 20 \mathrm{BP}$ & $1220-1252$ \\
House 56 & UCIAMS 118890 & $255 \pm 15 \mathrm{BP}$ & $1645-1657$ \\
House 56 & UCIAMS 118892 & $195 \pm 15 \mathrm{BP}$ & $1665-1676,1767-1771,1777-1787,1792-1800$, \\
TP2 & & $340 \pm 15 \mathrm{BP}$ & $1941-1950$ \\
TP3 & UCIAMS 76645 & $350 \pm 15 \mathrm{BP}$ & $1495-1523,1559-1562,1571-1602,1615-1630$ \\
\hline \hline
\end{tabular}

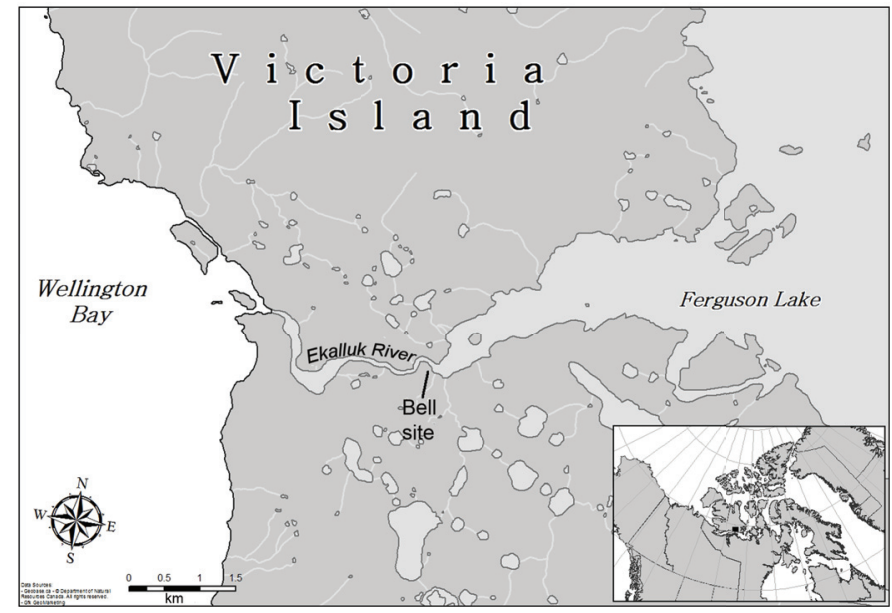

FIG. 1. Location of the Bell site within Iqaluktuuq, southeastern Victoria Island, Nunavut.

lagopus) and Rock Ptarmigan (Lagopus muta) (Parmalee et al., 1967).

\section{THE BELL SITE: LATE DORSET AND THULE CONTEXTS}

The Bell site (NiNg-2) is located in the Iqaluktuuq region (Fig. 1). William Taylor's extensive archaeological investigations at Iqaluktuuq in 1963, 1965, and 1988 yielded a dense distribution of occupations ranging from the PreDorset to Thule Inuit periods, providing what remains a centrally important data set for understanding the culture history of this part of the Canadian Arctic (Taylor, 1967, 1972). From 2000 to 2010, the region became the focus of the Iqaluktuuq Project, performed as a collaborative project by the Kitikmeot Heritage Society of Cambridge Bay and the University of Toronto. Over its decade of existence, the Iqaluktuuq project included intensive excavations at more than 10 sites, as well as high-resolution mapping of the region, and contributed material for use by the Kitikmeot Heritage Society in the community of Cambridge Bay (Friesen, 2002, 2004; Ryan, 2003, 2012; Howse, 2005, 2008, 2016; Griebel, 2010, 2013; Riddle, 2010).

The Bell site is located on the south side of the Ekalluk River, where the waters of Ferguson Lake enter the river (Fig. 1). It is a multi-component site containing evidence of Middle Dorset, Late Dorset, Thule Inuit, and Recent Inuit occupations. It includes a minimum of 10 Dorset and six Thule semi-subterranean houses, in addition to a large number of additional tent rings, caches, and unidentified features (Fig. 2). However, repeated reoccupations have undoubtedly obscured some earlier features.

\section{Late Dorset Contexts}

For this study, it was important to identify relatively unmixed faunal samples from similar contexts relating to Late Dorset and Thule occupations. Thus, for each culture we used samples from one house and two midden areas. The Late Dorset house assemblage comes from House 6 (H6), originally test-excavated by Taylor in 1988 and then fully excavated in 2002 (Ryan, 2012). The house was sub-rectangular in shape and measured $5.75 \times 4.5 \mathrm{~m}$. Its walls and interior were not well defined, except for the northwest corner, where a thick greasy cultural deposit and stone subfeatures indicated cooking activities. All faunal materials analyzed are from Level 4, identified as the Late Dorset occupational level on the basis of artifact typology (Ryan, 2012). Taylor obtained a radiocarbon date of 1035 \pm 125 BP for H6 (Canadian Archaeological Radiocarbon Database; Table 1).

In addition to selected faunal samples from H6, two midden squares were sampled. First, a test pit was placed in the $\mathrm{H} 6$ midden (H6M), $7 \mathrm{~m}$ in front of the entrance to the house. While one Thule artifact was located in the relatively shallow Level 3, all other artifacts from H6M are consistent with a Dorset occupation. Late Dorset artifacts were recovered down to the bottom layers; however, two Middle Dorset harpoon heads found in Levels 5 and 8 are interpreted as intrusive because of the Late Dorset artifacts found throughout the midden. Dating of H6M to the Late Dorset period is reinforced by a radiocarbon date of $940 \pm$ 15 BP from Level 9 near the bottom (Table 1). Fauna from Levels 5 and 6 of this midden were analyzed for the present report.

The second Late Dorset midden analyzed here is Test Pit 4 (TP4), located near the north end of the site and excavated in 2007 and 2010. The midden was $60 \mathrm{~cm}$ deep, with a total of seven levels. The artifacts excavated from the midden are largely indicative of a Late Dorset occupation; however, two Middle Dorset harpoon heads were found. Again, these 


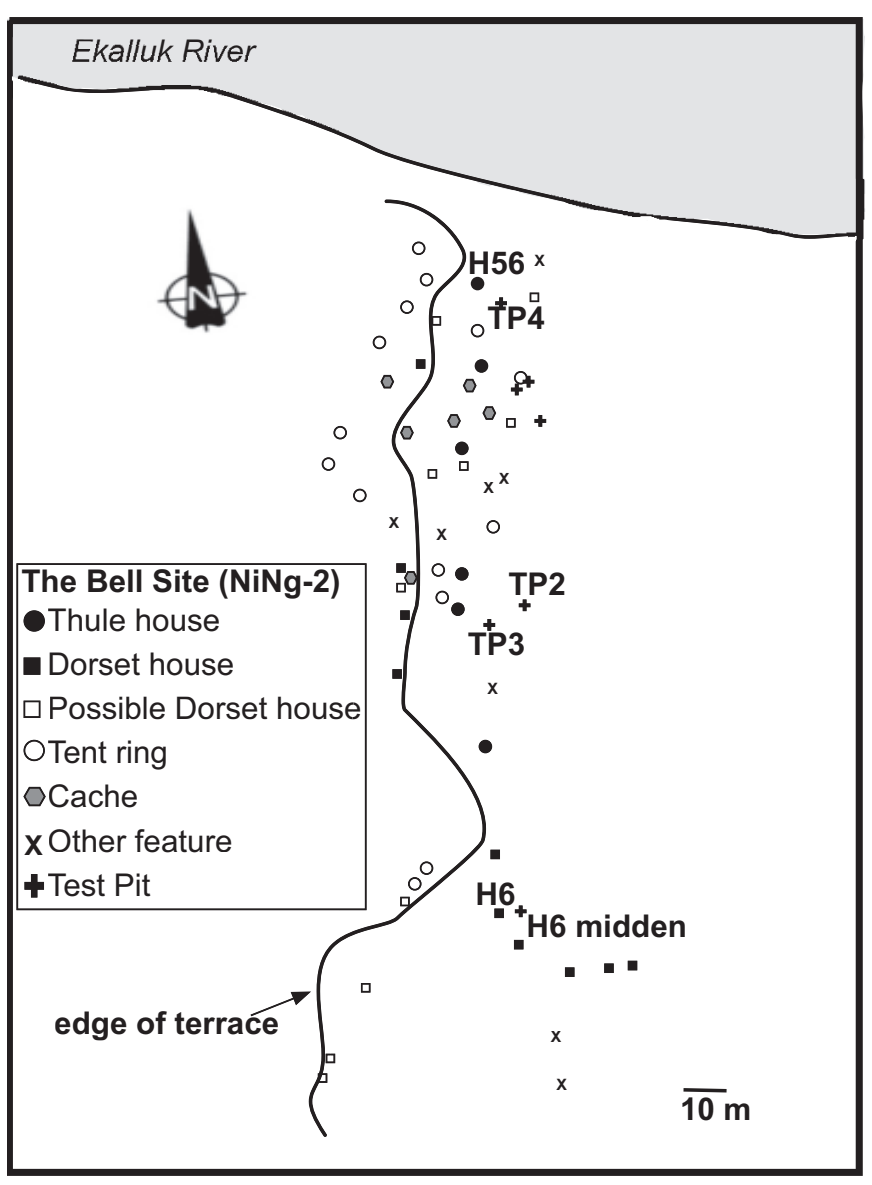

FIG. 2. Distribution of Thule and Dorset culture features at the Bell site, Victoria Island, Nunavut.

artifacts are likely intrusive, given that a radiocarbon date of $810 \pm 20$ BP (Table 1) obtained from the lowest layer, Level 7, places it squarely within the Late Dorset period. Fauna from Levels 4 and 7 were analyzed for this report.

\section{Thule Contexts}

The Thule house sample included in this study is from a test excavation in House 56 (H56), the northernmost house at the Bell site (Fig. 1). The house is deeply buried, and only the rough circular outline of the main room could be identified. In 2010, a $1 \times 1 \mathrm{~m}$ test unit was excavated at the rear of the structure. The unit contained five cultural levels and sublevels, at least three of which were floors. Although the artifacts are largely of Thule Inuit origin, a few Dorset artifacts were encountered in the lowest levels, presumably because the house was excavated into an earlier Dorset house or midden. Analyzed faunal materials are from Levels 2-4. Levels 5 and below, which include Dorset material, were excluded from the analysis. Radiocarbon dates from the upper levels of this feature are relatively late in the Inuit occupation of the site, falling between $255 \pm 15$ $\mathrm{BP}$ and $195 \pm 15 \mathrm{BP}$ (Table 1).

Two midden squares were also analyzed to represent the Thule occupation; both are located in front of Thule
House 7. TP2 was excavated in 2002, in eight levels. The artifacts recovered from Levels 1-5 were primarily of Thule origin, although Dorset artifacts, primarily small lithic flakes, were occasionally found. There are not enough radiocarbon dates to fully date TP2; however, Level 5, from which the faunal sample in this study was derived, yielded a date of $340 \pm 15$ BP (Table 1), indicating a likely 16th century age.

The TP3 midden is located $8 \mathrm{~m}$ away from TP2. Artifacts found in Levels 1-5 were primarily Thule, although a number of Dorset lithic flakes were identified, as in TP2. For present purposes, fauna from Levels $2-4 b$ were analyzed. A radiocarbon date of $350 \pm 15 \mathrm{BP}$ (Table 1) was recovered from Level 4.

The radiocarbon dates indicate that Late Dorset and Thule Inuit occupied the site sequentially. The Late Dorset contexts analyzed here date from the 11th to the 13th century CE, and the analyzed Thule contexts date from the 16th to the 18th century CE. For the remainder of this paper, we will compare the aggregated samples from the two periods, attempting to tease out areas of similarity and difference, and interpret them in light of broader aspects of Late Dorset and Thule societies.

\section{COMPARING LATE DORSET AND THULE ARCHAEOFAUNAS}

Before proceeding to a comparison of the two samples, we must discuss the degree to which the samples are equivalent. As a starting point, it is important to emphasize that all Late Dorset and Thule assemblages analyzed for this study were recovered with identical field methods, using $3 \mathrm{~mm}(1 / 8 \mathrm{inch})$ mesh screens. They were also analyzed by the same analyst using the same reference collection, and thus all aspects of recovery and analysis are virtually identical.

In terms of taphonomy, in both cases the bones appear to have been buried fairly rapidly; from all contexts, most bones were extremely well preserved, and all were in early stages of weathering (Stages 1-3; Behrensmeyer, 1978). While the caribou element distributions outlined below are positively correlated with bone density (Table 2), the fact that these same assemblages contain many very delicate bones, as well as wood and in some cases even skin, indicates that most are not heavily affected by postdepositional processes. The taphonomic factor that we expect to be most different between the two contexts is the degree of carnivore gnawing, since dogs were common in the Thule period, but likely were completely absent in the Late Dorset period. This difference is borne out in the present sample. Dog bones were identified in the TP2 and H56 Thule samples from the Bell site (Table 3), and dog-sized puncture marks were recorded on several Thule period bones, whereas all punctures on Late Dorset bones were smaller, indicating gnawing by Arctic foxes (Darwent, 2004). In terms of actual gnaw mark frequencies, $2.5 \%$ of 
TABLE 2. Caribou bone rank order correlation for each context using Spearman's rho. Element frequencies, expressed as percent minimum animal units (\% MAU), are compared to bone density and three utility indices (see text for description and references).

\begin{tabular}{|c|c|c|c|c|c|c|}
\hline \multirow[b]{2}{*}{ Index } & \multicolumn{3}{|c|}{ Late Dorset } & \multicolumn{3}{|c|}{ Thule Inuit } \\
\hline & ТP4 & H6M & H6 & TP2 & TP3 & H56 \\
\hline Density & $\mathrm{r}_{\mathrm{s}}=0.77, p \leq 0.001$ & $\mathrm{r}_{\mathrm{s}}=0.75, p \leq 0.001$ & $\mathrm{r}_{\mathrm{s}}=0.84, p \leq 0.001$ & $\mathrm{r}_{\mathrm{s}}=0.52, p=0.04$ & $\mathrm{r}_{\mathrm{s}}=0.57, p=0.02$ & $\mathrm{r}_{\mathrm{s}}=0.87, p \leq 0.001$ \\
\hline Food utility & $\mathrm{r}_{\mathrm{s}}=0.25, p=0.248$ & $\mathrm{r}_{\mathrm{s}}=0.19, p=0.311$ & $\mathrm{r}_{\mathrm{s}}=0.24, p=0.204$ & $\mathrm{r}_{\mathrm{s}}=-0.15, p=0.44$ & $\mathrm{r}_{\mathrm{s}}=-0.21, p=0.27$ & $\mathrm{r}_{\mathrm{s}}=-0.07, p=0.71$ \\
\hline Meat drying & $\mathrm{r}_{\mathrm{s}}=-0.74, p \leq 0.001$ & $\mathrm{r}_{\mathrm{s}}=-0.84, p \leq 0.001$ & $\mathrm{r}_{\mathrm{s}}=-0.72, p \leq 0.001$ & $\mathrm{r}_{\mathrm{s}}=-0.49, p=0.03$ & $\mathrm{r}_{\mathrm{s}}=-0.66, p=0.002$ & $\mathrm{r}_{\mathrm{s}}=-0.67, p=0.002$ \\
\hline Unsaturated marrow & $\mathrm{r}_{\mathrm{s}}=0.64, p=0.03$ & $\mathrm{r}_{\mathrm{s}}=0.88, p \leq 0.001$ & $\mathrm{r}_{\mathrm{s}}=0.84 ; p \leq 0.001$ & $\mathrm{r}_{\mathrm{s}}=0.58, p=0.06$ & $\mathrm{r}_{\mathrm{s}}=0.55, p=0.08$ & $\mathrm{r}_{\mathrm{s}}=0.83, p=0.002$ \\
\hline
\end{tabular}

specimens in the combined Thule sample and $1.3 \%$ of the specimens in the combined Dorset context show evidence of gnawing (Table 4). Finally, the measure of fragmentation, calculated as the ratio of number of identified specimens (NISP) to minimum number of elements (MNE), is similar in both the Late Dorset and Thule contexts, which suggests that bone elements were broken into similar sizes and numbers of pieces by both groups. However, the samples from the Thule contexts had a higher proportion of fragmented elements (the \% fragmentary measure, Table 4). This measure was consistent across the three Thule contexts and indicates that the majority of the identified bones were not whole elements. While there is only a slight difference in the frequency of gnaw marks, dog activities are potentially responsible for the higher frequency of $\%$ fragmentary in the Thule contexts and may also have influenced class frequencies, though it is difficult to quantify the precise impact.

Thus, except for the impacts of Thule dogs, which are assumed to be significant, these samples have similar taphonomic histories, and a comparison of broad patterns is justified. For the following comparisons, each context represents an extended period of deposition and a palimpsest of many activities. For present purposes, we aggregate all samples for each period to increase the sample sizes and allow the broadest level of comparison possible between the two periods.

\section{Taxonomic Distribution}

Samples analyzed from the two occupations at the Bell site were similar in size: the three Late Dorset contexts provide a sample of 16240 specimens, of which $59 \%(\mathrm{n}=$ 9609) have been identified at least to class, and the three Thule faunal samples total 16719 bone specimens, of which $77 \%(\mathrm{n}=12805)$ have been so identified (Table 3$)$. Within each occupation, class distribution among the different features is quite variable. In terms of overall class distribution, the samples are similar in a general sense (Fig. 3; Table 3), though differences between the Late Dorset and Thule samples are statistically significant $\left(\chi^{2}=258.62, p<0.01\right)$. In both samples, mammals are most frequent, followed by fish, with birds a distant third. Mammals are much more frequent than fish (60\% vs. $36 \%)$ in the Late Dorset sample, whereas they outnumber them only slightly $(51 \%$ vs. $46 \%)$ in the Thule sample. Thus, higher frequencies of fish bones in the Thule contexts can be seen to be the most significant class-level difference. It is likely that the original differences between the two occupations were even greater but have been reduced by taphonomic factors. Specifically, Thule period dogs are likely to have consumed many fish, completely destroying their bones in the process (see Whitridge, 2001).

With the exception of a few sculpin bones in the Thule sample, all fish specimens belong to Arctic char and lake trout. Few elements can be used to distinguish these species confidently, and therefore the majority of specimens $(89 \%$ for Late Dorset and $88 \%$ for Thule) could not be identified below the genus Salvelinus (Fig. 4). However, those that could be identified to species show a noteworthy difference in their proportions: Arctic char make up 78\% (100/128) of Salvelinus specimens identified to species for Late Dorset, but only $61 \%(116 / 190)$ for Thule. Thus, while Arctic char is the most frequent taxon in both samples, it dominates in the Late Dorset sample, but Arctic char and lake trout are much closer in terms of contribution to the economy in the Thule sample.

At a general level, bird frequencies are similar for the two periods: migratory waterfowl (geese, ducks, and swans) dominate, with geese most common in both periods (Fig. 5). However, there are differences; migratory waterfowl overall are much more common in Thule contexts, where they comprise $91 \%(150 / 165)$ of identified birds, as opposed to only 69\% (124/179) in Late Dorset contexts. This difference reflects the greater diversity of bird species found in the Late Dorset features, including jaegers, gulls, and Sandhill Crane. Additionally, ptarmigan, a year-round Arctic resident, is almost twice as frequent in Late Dorset contexts as it is in the Thule contexts (Table 3).

Some noteworthy differences also occur in mammal frequencies at the site (Fig. 6). Late Dorset occupants acquired a slightly broader range of species, since wolverine and polar bear were identified in Late Dorset samples, but were absent from the Thule Inuit samples. The only taxon present in the Thule Inuit sample and absent in the Late Dorset sample is dog. Overall, caribou is by far the most frequent mammal in all features, but is more common in the Thule Inuit assemblage, where it represents $89 \%$ of all identified mammals, as opposed to $64 \%$ in Late Dorset. Notably, Late Dorset samples contained higher frequencies of Arctic fox and seal in comparison to Thule samples: Arctic fox accounts for $27 \%$ of the identified mammal specimens in the Late Dorset assemblage, which is almost four times its frequency (7\%) in the Thule contexts. Cut 
TABLE 4. Frequency of modifications on mammal bones from the Bell Site.

\begin{tabular}{|c|c|c|c|c|c|c|c|c|}
\hline \multirow[b]{2}{*}{ Modification } & \multicolumn{4}{|c|}{ Late Dorset } & \multicolumn{4}{|c|}{ Thule Inuit } \\
\hline & TP4 Midden & H6 Midden & House 6 & Total & TP2 Midden & TP3 Midden & House 56 & Total \\
\hline Cut marks & 22 & 18 & 46 & 86 & 8 & 13 & 12 & 33 \\
\hline$\%$ cut marks ${ }^{1}$ & 0.8 & 1.2 & 3.4 & 1.5 & 0.3 & 0.5 & 0.8 & 0.5 \\
\hline Gnaw marks & 6 & 19 & 50 & 75 & 49 & 73 & 43 & 165 \\
\hline$\%$ gnaw marks ${ }^{1}$ & 0.2 & 1.2 & 3.7 & 1.3 & 2.0 & 2.7 & 3.0 & 2.5 \\
\hline Burn marks & 207 & 28 & 43 & 278 & 1 & 89 & 60 & 150 \\
\hline$\%$ burn marks ${ }^{1}$ & 7.2 & 1.8 & 3.2 & 4.8 & 0.04 & 3.3 & 4.2 & 2.3 \\
\hline$\%$ fragmentary $^{1}$ & 38.2 & 62.7 & 76.3 & 66.4 & 86.2 & 90.4 & 84.6 & 87.3 \\
\hline Fragmentation (NISP:MNE) ${ }^{2}$ & 2.5 & 2.1 & 2.2 & 2.3 & 2.7 & 2.2 & 3.5 & 2.9 \\
\hline NISP $^{3}$ & 1545 & 754 & 634 & 2933 & 678 & 585 & 416 & 1679 \\
\hline $\mathrm{MNE}$ & 955 & 502 & 375 & 1832 & 311 & 237 & 165 & 713 \\
\hline Whole elements & 554 & 281 & 150 & 985 & 93 & 56 & 64 & 213 \\
\hline
\end{tabular}

${ }^{1}$ Percentages are calculated using total mammal NISP for each sample (see Table 3).

${ }^{2}$ Following Lyman (2008), whole elements are excluded from this calculation.

${ }^{3}$ This NISP is used for calculating fragmentation and excludes mammal bone specimens that could not be identified beyond class.
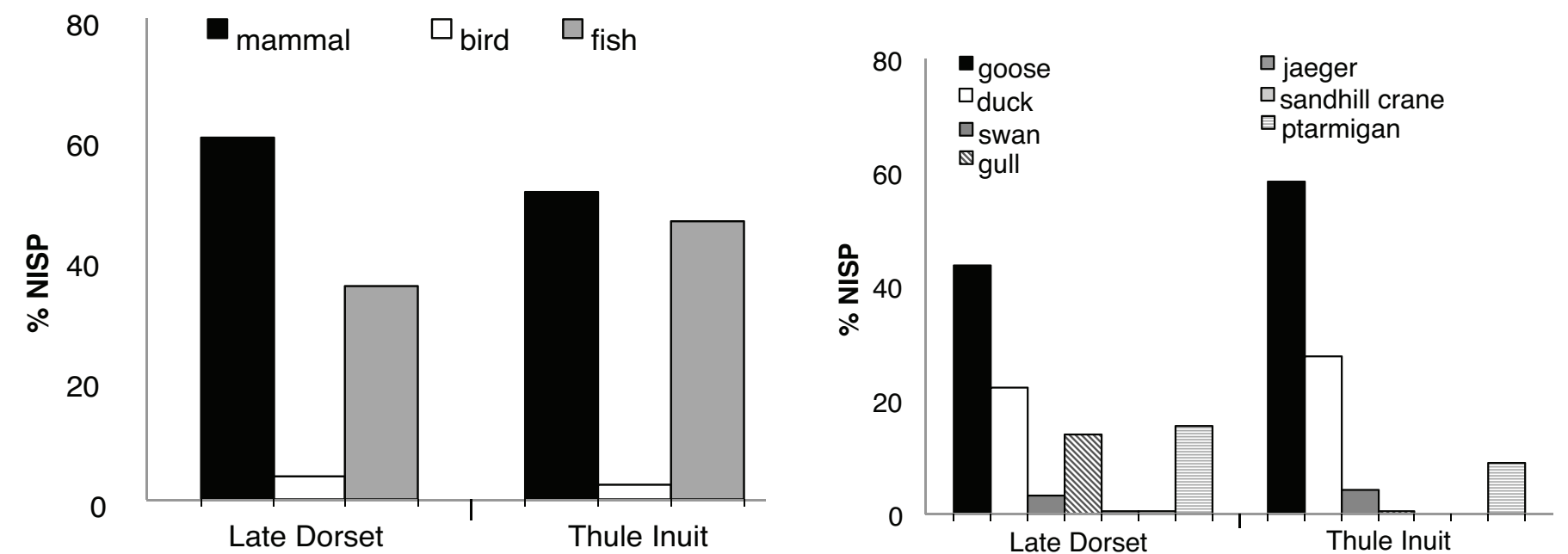

FIG. 3. Class frequencies at the Bell site expressed as \% NISP.

FIG. 5. Distribution of birds at the Bell site expressed as \% NISP.
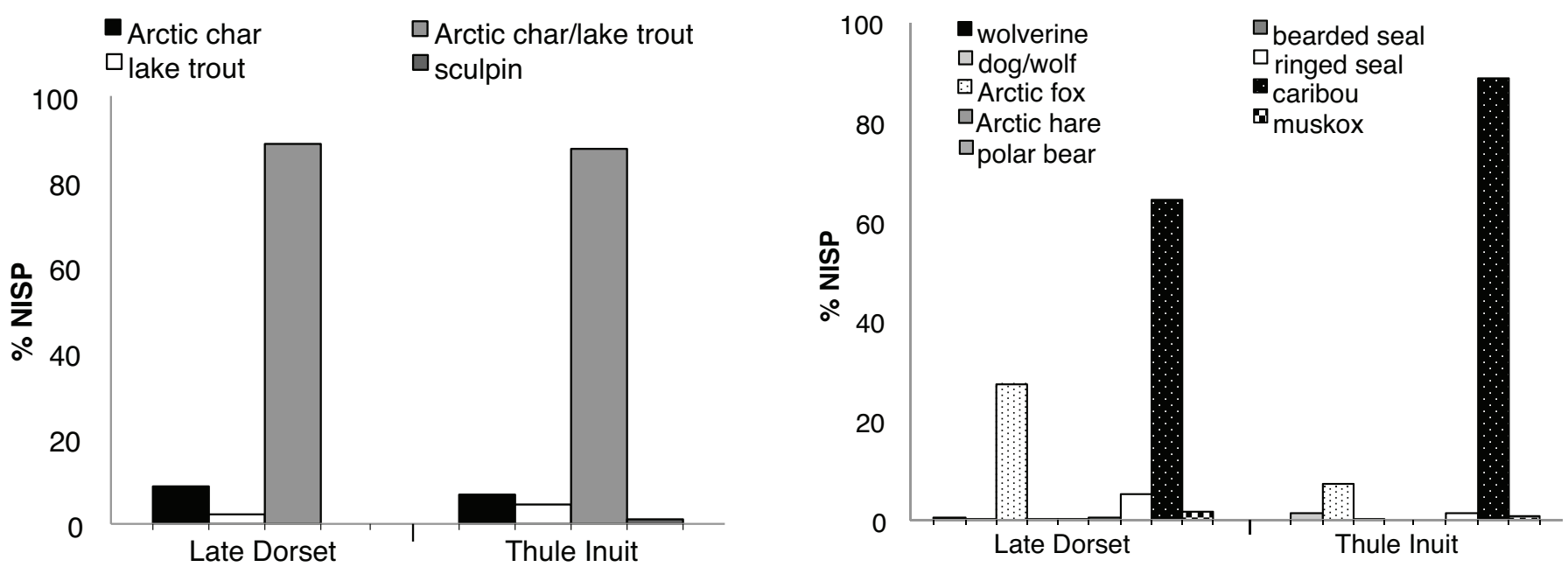

FIG. 4. Distribution of fish at the Bell site expressed as \% NISP.

FIG. 6. Distribution of mammals at the Bell site expressed as \% NISP. 


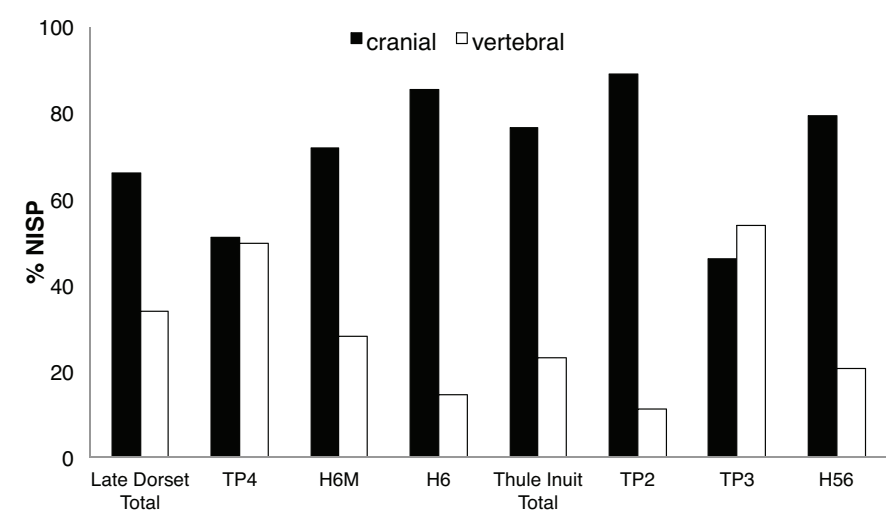

FIG. 7. Distribution of Salvelinus skeletal portions at the Bell site expressed as $\%$ MAU.

marks identified on Arctic fox specimens from the Late Dorset and Thule Inuit contexts suggest that both groups actively hunted Arctic foxes. It is difficult to infer whether they processed these animals for meat as well as for fur, but it is clear that the foxes were not intruders who came to the area solely for denning. Seal accounts for $6 \%$ of the identified mammal specimens in the Late Dorset contexts, but only $2 \%$ in the Thule Inuit contexts.

\section{Element Distributions}

The fish specimens discussed in this section include all those identified to the genus Salvelinus. For the present study, we seek to quantify only one very broad expression of element frequency: the ratio of cranial to vertebral specimens. This ratio is potentially useful for taphonomic interpretation, since vertebrae of salmonids tend to be denser and therefore more resistant to destruction than their cranial bones (Butler and Chatters, 1994). To quantify crania, we included a list of 29 commonly occurring midline and paired elements; this number was divided by 52 , the number in a single skull, to yield a cranial minimum animal unit (MAU). The total number of vertebrae was divided by 65 , the average number in an Arctic char (Morrow, 1980), to yield the corresponding vertebral MAU. From these numbers, we calculated the percentage of cranial MAU within the combined cranial/vertebral sample to indicate variability across the three contexts. The distributions of Salvelinus elements, as quantified in the ratio of cranial to vertebral specimens, are quite similar between the two periods. As seen in Figure 7, the ranges across the three samples within each period are similar, with cranial bones more frequent than vertebral in all but one case, and for both periods the house samples have among the highest proportions of cranial elements. Thus, density-mediated attrition appears not to have been the primary factor in determining fish element distribution. Instead, it seems most likely that the low frequency of vertebral elements in the house resulted from processing and consumption processes.
We quantified caribou element distributions by calculating minimal animal units (MAUs), which standardizes elements according to the number of each occurring in a single animal. MAUs are expressed as percentages in order to demonstrate the relative abundance of the different elements. Throughout all of the features analyzed, the distribution of caribou element frequencies remains fairly consistent: the entire carcass is represented, and vertebrae are relatively rare. For caribou element distributions, there is some variability among the three assemblages within each period (Table 5); however, within all features, the distributions of caribou elements are positively and strongly correlated with the caribou density index (Table 2; Lam et al., 1999). Such a pattern normally indicates that destructive taphonomic agents have played some role in the formation of the faunal assemblage. When $\%$ MAUs are compared to the caribou food utility index (Metcalfe and Jones, 1988), no significant relationship is found, indicating that elements are not preferentially present, or absent, because of the total amount of meat and marrow attached to them. In addition, all features had element distributions with negative but significant relationships to the meat drying index, possibly indicating that meat was dried at the site and then transported elsewhere for consumption (see Howse, 2008). When caribou element \% MAUs were compared with the caribou unsaturated marrow index (Morin, 2007), a positive and significant relationship with this index was identified in each context, though the strength of the relationship varied (TP4; H6M; H6). This result suggests that marrow processing may have played a role in these element distributions.

To compare the two periods further, we have aggregated all element frequencies within each period and recalculated the aggregate MAUs (Fig. 8). Rank order correlation indicates a strong positive correlation between the two sets of element distributions $\left(\mathrm{r}_{\mathrm{s}}=0.58875, p=0.00049\right)$. Thus, we conclude that on the whole, acquisition, processing, and consumption of caribou were relatively similar for the two periods.

\section{Modification Frequencies}

Though modifications were recorded on all specimens, this section focuses on mammals and excludes the less robust fish and bird bones (Table 4). Cut marks are found on all mammal species, but are present on only a small proportion of the identified bones. However, cut marks are more than twice as frequent on Late Dorset specimens as on their Thule counterparts (Table 4). Reasons for this pattern are not clear, but might relate to the fact that most Dorset cutting implements were probably either microblades or bifacial knives, while Thule blades were almost exclusively made of ground slate or metal. Burning is also slightly more common in the Late Dorset assemblage, where it affects $4.8 \%$ of the identified mammal bones, as opposed to $2.3 \%$ of the Thule bones. As noted earlier, on the Late 
TABLE 5. Caribou skeletal element abundance at the Bell site expressed as percent minimum animal units (\% MAU).

\begin{tabular}{|c|c|c|c|c|c|c|}
\hline Element ${ }^{1}$ & TP4 Midden & H6 Midden & House 6 & TP2 Midden & TP3 Midden & House 56 \\
\hline Cranium & 76.9 & 82.4 & 88.9 & 66.7 & 80.0 & 100.0 \\
\hline Mandible & 30.8 & 100.0 & 100.0 & 100.0 & 30.0 & 50.0 \\
\hline Atlas & 30.8 & 11.8 & 44.4 & 44.4 & 20.0 & 0.0 \\
\hline Axis & 0.0 & 11.8 & 22.2 & 0.0 & 0.0 & 0.0 \\
\hline Cervical & 12.3 & 18.8 & 8.9 & 0.0 & 8.0 & 10.0 \\
\hline Thoracic & 7.7 & 5.9 & 13.3 & 17.8 & 8.0 & 5.0 \\
\hline Lumbar & 9.2 & 3.5 & 6.7 & 2.2 & 0.0 & 0.0 \\
\hline Caudal & 0.0 & 1.2 & 2.2 & 0.0 & 0.0 & 0.0 \\
\hline Sacrum & 3.1 & 7.1 & 4.4 & 4.4 & 0.0 & 0.0 \\
\hline Rib & 20.0 & 15.3 & 84.4 & 13.3 & 8.0 & 25.0 \\
\hline Sternum & 20.0 & 5.9 & 22.2 & 28.9 & 0.0 & 10.0 \\
\hline Scapula & 30.8 & 41.2 & 44.4 & 44.4 & 30.0 & 50.0 \\
\hline Humerus-p & 46.2 & 35.3 & 11.1 & 11.1 & 10.0 & 0.0 \\
\hline Humerus-d & 46.2 & 17.6 & 33.3 & 22.2 & 0.0 & 0.0 \\
\hline Radius/ulna-p & 53.8 & 11.8 & 44.4 & 44.4 & 30.0 & 50.0 \\
\hline Radius/ulna-d & 61.5 & 17.6 & 11.1 & 0.0 & 30.0 & 50.0 \\
\hline Metacarpal-p & 53.8 & 5.9 & 55.6 & 22.2 & 40.0 & 0.0 \\
\hline Metacarpal-d & 23.1 & 58.8 & 33.3 & 55.6 & 30.0 & 25.0 \\
\hline Carpal & 30.8 & 9.4 & 24.4 & 17.8 & 8.0 & 10.0 \\
\hline Innominate & 38.5 & 11.8 & 44.4 & 66.7 & 30.0 & 50.0 \\
\hline Femur-p & 100.0 & 17.6 & 22.2 & 11.1 & 10.0 & 0.0 \\
\hline Femur-d & 23.1 & 5.9 & 11.1 & 0.0 & 30.0 & 0.0 \\
\hline Tibia-p & 30.8 & 17.6 & 44.4 & 44.4 & 40.0 & 50.0 \\
\hline Tibia-d & 7.7 & 29.4 & 11.1 & 44.4 & 30.0 & 75.0 \\
\hline Fibula & 46.2 & 17.6 & 22.2 & 11.1 & 10.0 & 50.0 \\
\hline Astragalus & 23.1 & 11.8 & 44.4 & 0.0 & 20.0 & 25.0 \\
\hline Calcaneum & 23.1 & 0.0 & 33.3 & 66.7 & 90.0 & 0.0 \\
\hline Tarsal & 20.0 & 11.8 & 22.2 & 4.4 & 16.0 & 15.0 \\
\hline Metatarsal-p & 53.8 & 23.5 & 44.4 & 22.2 & 100.0 & 0.0 \\
\hline Metatarsal-d & 38.5 & 82.4 & 22.2 & 33.3 & 10.0 & 75.0 \\
\hline Phalanges & 38.5 & 34.1 & 31.1 & 22.2 & 16.0 & 45.0 \\
\hline
\end{tabular}

${ }^{1} \mathrm{p}=$ proximal, $\mathrm{d}=$ distal.

Dorset specimens, all gnawing appears as puncture marks 2-3 $\mathrm{mm}$ in diameter, which suggests that the bones were gnawed by Arctic foxes (Darwent, 2004). Several puncture marks identified on the Thule Inuit specimens were in the 5-6 $\mathrm{mm}$ diameter range, which matches the expectation for dog gnawing; however, the majority of gnaw marks were present in the form of scores, furrows, and pits, which tend to result from prolonged chewing on the bone itself, rather than from meat removal (Binford, 1981). Finally, fragmentation frequencies were discussed above in connection to taphonomy; however, they may also relate in part to intensity of marrow breakage and, potentially, to production of bone grease. Thus, the slightly higher levels of fragmentation in the Thule samples might relate to processing-related activities, as well as to the impact of dogs mentioned previously.

\section{Seasonality and Prey Demography}

The faunal list provides a variety of seasonal indicators. Summer migrants, including goose, duck, gull, and other bird species, are present in all features, while the yearround resident ptarmigan accounts for $16 \%$ of the Late Dorset identified bird specimens, but only $9 \%$ of the Thule Inuit bird sample. The large numbers of caribou and fish found in both samples indicate that Late Dorset and Thule Inuit likely took advantage of the region's productive upstream Arctic char run in late summer, as well as the early fall caribou migration. However, it is not possible to conclude from the faunal list alone whether or not the site's occupants were present during other seasons. We therefore considered the age distributions of prey species, giving specific attention to immature individuals.

Immature birds were found in all three of the Late Dorset contexts, as expected given the fact that they are summer migrants. More precise information is given by a goose femur from TP4, which exhibited significant deposits of medullary bone associated with egg-laying, indicating that Late Dorset were at the site sometime in May or early June. In the Thule Inuit contexts, at least one immature eider duck and two immature geese were present in TP2, and one immature goose was also identified in TP3. These immature geese were quite similar in size and morphological development to a six-week-old goose in the reference collection. Thus, they were likely acquired in July or August.

The fusion sequence of ringed seals was used to estimate age at death (Storå, 2002). Elements that fuse in the first year of life do so before the animal's sixth month, providing the best way to narrow down the season during which an animal was killed. Sample sizes were small; however, animals killed before they were six months old were found in each Late Dorset context. We identified a fetal or newborn individual on the basis of a small, very porous 


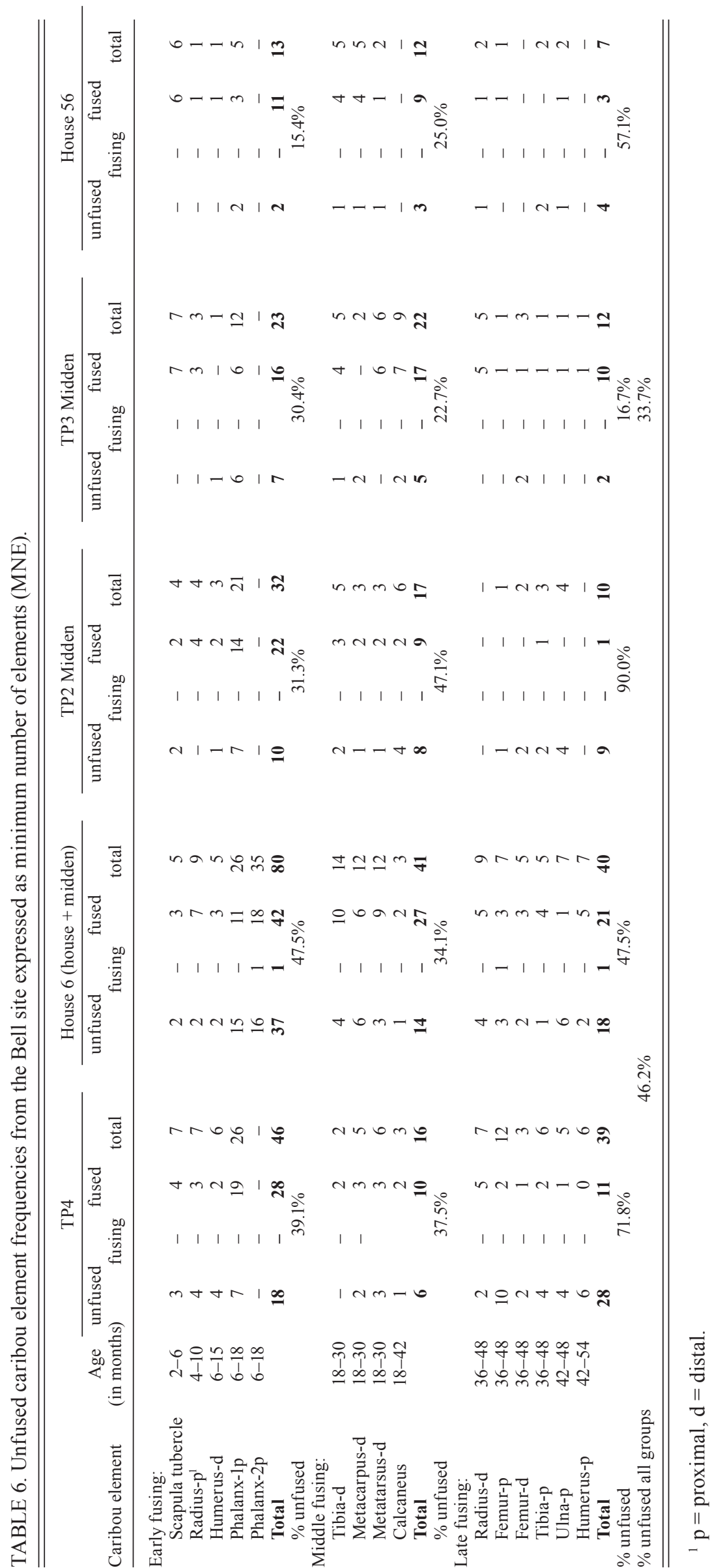

pelvis with an unfused acetabulum, which placed its death between March and May. Two yearlings were also identified on the basis of scapulae with unfused supraglenoid tubercles, which indicated that they were killed between April and September. The very small sample of seals in the Thule contexts does not yield much usable demographic information; however, epiphyseal fusion indicates that all seals were at least one year of age when they were killed.

The epiphyseal fusion sequence for caribou elements was also considered (Hufthammer, 1995). In the Late Dorset contexts, a minimum of five calves aged between two and six months were killed sometime between August and December. Another four were aged between four and 10 months, which places their death between October and April (Table 6). In the Thule contexts, at least two calves in TP2 were between two and six months of age, which indicates that their death occurred between August and December (Table 6). While these data do not translate directly into prey demography, in both samples, the elements fused within the middle and late fusing stages indicate that adult animals were also taken.

Caribou tooth eruption sequences were also considered on the basis of Miller's study of barren-ground caribou (Miller, 1974; Table 7). In the Late Dorset contexts, mandibles from two calves exhibiting the first molar erupting indicate that the animals were killed between September and November. Another mandible, from H6M, exhibited an erupted $\mathrm{M} 1$ and absent M2, indicating it belonged to an individual killed between December and April. We also identified a mandible exhibiting an erupted M1 and M2 with deciduous premolars, indicating it was killed between October and March. In the Thule Inuit contexts, only one specimen yielded usable data. This specimen, which has deciduous premolars and an erupting M1, belonged to a calf between three and five months of age, which places its death between September and November.

At a gross level, the class frequencies and species frequencies within each class indicate a broad level of similarity in taxa acquired and, by extension, in seasons when the two societies lived at Iqaluktuuq. The few differences include the single Late Dorset goose bone with medullary deposits, the single Late Dorset fetal seal bone, and the four Late Dorset calves that died at four to 10 months of age. However, sample sizes are small, so the lack of similar indicators in the Thule sample cannot be taken as conclusive evidence that 
TABLE 7. Caribou tooth eruption data from Late Dorset contexts at the Bell site.

\begin{tabular}{lllcc}
\hline \hline Tooth eruption $^{1}$ & Ages & TP4 Midden & H6 Total & Total \\
\hline M1 absent & $0-2$ months & - & - & - \\
M1 erupting & $3-5$ months & 1 & 1 & 2 \\
M1 erupted, M2 absent & $6-9$ months & - & 1 & 1 \\
M2 erupting & $10-15$ months & - & - & - \\
M2 erupted, deciduous PM & $16-21$ months & 1 & - & 1 \\
PM erupting & $22-29$ months & - & - & - \\
\hline \hline
\end{tabular}

${ }^{1} \mathrm{M}=$ molar, $\mathrm{PM}=$ premolar.

Thule were not present at the site during similar periods. Furthermore, individual faunal elements do not necessarily indicate occupation during the season of the animal's death; they could have been stored or transported from earlier seasonal occupations elsewhere.

Despite these caveats, there is a general trend for more spring indicators in the Late Dorset sample. These data suggest that Late Dorset may have arrived at the Bell Site sometime during early spring, in April or May, and stayed at least until the fall caribou migration was over in late October or early November. It is unclear how much time they spent at Iqaluktuuq in winter, when they would have been eating primarily stored caribou and Arctic char. There is no indication that Thule Inuit arrived at the site before early summer, though we cannot rule this out. However, the higher frequency of lake trout, which can be caught in nearby Ferguson Lake throughout the year, may suggest that Thule Inuit remained in the area for a greater proportion of the winter. We will return to this discussion below.

In terms of prey demography, our best evidence comes from caribou epiphyseal fusion. This data class indicates that Late Dorset hunted a larger proportion of young animals than Thule did. For the Late Dorset contexts $(n=262), 46.9 \%(n=123)$ were from individuals younger than four and a half years, and $21 \%(\mathrm{n}=56)$ were from individuals younger than 18 months (Table 6). However, from the Thule contexts $(n=148$, only $33.8 \%(n=50)$ of the caribou were from individuals younger than four and a half years, and only $12.8 \%(\mathrm{n}=19)$ came from individuals younger than 18 months. These differences, however, are not statistically significant $\left(\chi^{2}=5.09, p=0.078\right)$.

\section{DISCUSSION}

When considered together, these diverse aspects of the two archaeofaunal assemblages indicate broad similarities between Late Dorset and Thule Inuit subsistence and settlement patterns at the Bell site. Both are based largely on the acquisition of caribou and Arctic char-an unsurprising result, given that these same two species drew Inuit to this region well into the 20th century. By extension, the dominance of caribou and char at a site with semisubterranean houses and extensive middens is de facto evidence for a significant level of storage. The upstream Arctic char run, occurring from mid-August to midSeptember, and the fall caribou migration, which occurs mainly in September and October, are both limited duration events, which could have supplied large amounts of food only if their products were stored for later consumption.

Similarities do not end there. Both societies obtained migratory waterfowl in limited numbers, fished for lake trout in addition to char, and acquired many of the same secondary mammal and bird resources. Furthermore, comparison of caribou and Arctic char element distributions indicate that, at a gross level, both societies seem to have butchered, transported, processed, and discarded these taxa in a similar manner.

Beyond these major similarities, a number of subtle differences occur. Most generally, the Thule Inuit economy appears to be somewhat more focused on a few central taxa than its Late Dorset counterpart. This is most evident in the mammal assemblage, with caribou making up a significantly higher proportion in the Thule period than it did in the Late Dorset period. Late Dorset had higher proportions of an array of secondary mammalian taxa, including Arctic fox, muskox, and seal. Likewise, Late Dorset acquired more birds than the Thule Inuit, both in terms of total contribution to diet and in terms of number of species, again indicating greater reliance on secondary species. Fish, on the other hand, run counter to this general pattern, in that Thule relied on Arctic char and lake trout in relatively equal proportions, as opposed to the Late Dorset concentration on char. Thule also ate more fish overall than did Late Dorset, a pattern particularly noteworthy given that fish numbers were likely depressed in the Thule period by the presence of dogs.

There is also a trend towards a wider array of age classes, and particularly a higher proportion of younger individuals, among mammals in the Late Dorset period. This is particularly true in the caribou sample, but is also seen in more young muskox, fox, and seal bones. It must be acknowledged, however, that this result is based on a small number of precisely aged specimens from each period.

To understand the implications of these differences, we consider three categories of possible contributing factors: those relating to climate, seasonality, and technology. In terms of climate, the bulk of the Late Dorset occupation occurred during the Medieval Warm Period, while the Thule contexts analyzed here were significantly later, falling at least in part within the Little Ice Age (Miller et al., 2010). Although both of these periods are imprecisely dated, regionally variable, and incorporate variability at annual and decadal scales, they do represent broad climate trends that could, hypothetically, have an impact on the regional ecosystem with ripple effects on subsistence economies. However, we are unable to evaluate this factor fully, beyond pointing out that the range of resources available during both periods appears to be virtually identical, and that in this region it is currently unclear how different warming and cooling scenarios might have 


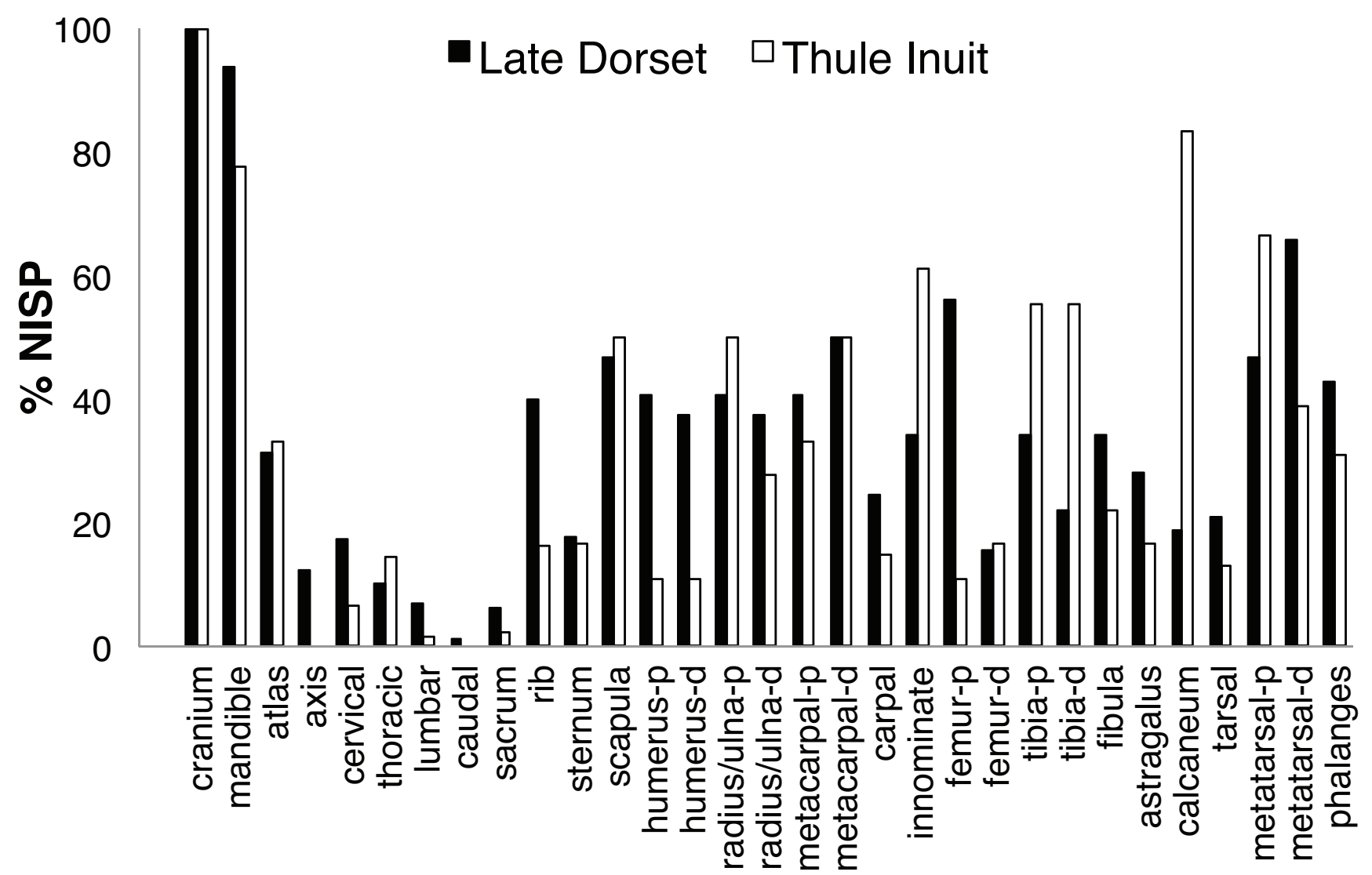

FIG. 8. Distribution of caribou skeletal elements at the Bell site expressed as $\%$ MAU. The ends of long bones were tallied separately $(p=$ proximal end, $d=$ distal end).

affected primary subsistence resources. Put another way, we do not have any straightforward evidence indicating that any of the differences we see between Late Dorset and Thule are a result of different species densities in the past.

A second set of factors potentially influencing these differences is related to season of site occupation. We have elaborated on this possible influence above, but reiterate here that faunal indicators are imperfect reflections of site seasonality. Furthermore, an argument that seeks to use faunal information to determine season of occupation and then turns around and uses season of occupation to interpret the reasons for faunal differences is bound to be somewhat circular. We do have one independent line of evidence, however, which is that both Late Dorset and Thule lived in substantial semi-subterranean houses at the Bell site; such housing is normally interpreted as indicating the intent to live in these dwellings for at least part of the cold season, and we have no doubt that this is the case here. Thus, both occupations are anchored by the timing of the char run and caribou migration, as well as the intent to live on site for at least part of the cold season. Two questions remain: how soon before the char run (August) did they arrive, and how late into the winter did they stay? These questions are complicated by the fact that we do not have a complete picture of the full annual settlement pattern of either group, and the possibility that one or both moved out onto the sea ice to hunt seals at breathing holes in winter, like the
Inuinnait groups who lived in the region in the 19th and 20 th centuries. For now, we can say only that the greater frequency of waterfowl in the Late Dorset assemblage and the few specific seasonal indicators described above may indicate that the Late Dorset groups arrived at the site earlier in spring, and that the greater proportion of lake trout relative to Arctic char in the Thule assemblage may indicate that the Thule remained at the site for a greater part of the winter. This last interpretation, however, is a textbook example of potential equifinality, in that it is equally possible that the greater frequency of lake trout in the Thule period results from their more specialized fishing technology, a point we return to below.

The third set of factors, related to the impacts of technological differences, is in many ways the most complex. There is a long list of Thule technologies that seem significantly more efficient or effective than their Late Dorset counterparts, and we can therefore hypothesize that they affected the acquisition, transport, processing, and preparation of food. We will assess a few of the most relevant here, while ignoring others (such as harpoon technology) that are less important in this location given the focus on terrestrial and riverine resources.

Several categories of technology appear, rather counterintuitively, to have had a negligible impact on the observed faunal differences. For example, Thule transportation technology, which included umiaks (large, 
open skin boats) and dogsleds, was clearly capable of efficiently transporting greater quantities of materials than comparable Dorset transport. Our most direct test of this factor is seen in the degree of culling of caribou and fish as represented by element distributions: the assumption is that as transport costs increase, greater culling of low-utility elements will occur to reduce weight. However, in this case, we found broad similarities between element distributions from Late Dorset and Thule assemblages, perhaps because the two major species, caribou and Arctic char, were both obtained within a few kilometres of the site. Another technological category that is not reflected in the faunal record is that of Thule bird-hunting technologies, which included specialized bird spears. However, these spears do not seem to have resulted in more frequent acquisition of birds.

Two categories of technology, however, stand out as having potentially significant impacts on the observed archaeofaunal differences. The first is the use of bows and arrows by Thule Inuit, but not Dorset. Bows and arrows are superior weapons: they allow more accurate shooting over greater distances and therefore higher return rates and greater selectivity in targeting particular prey individuals (Sisk and Shea, 2009; Kennett et al., 2013). In fact, differences between Inuit bows and arrows and Dorset spears or lances have been shown to directly affect the construction and use of caribou drive lanes at Iqaluktuuq (Friesen, 2013). In the present study, differential success rates for hunting caribou are suggested by two data sets. First, the Mammalia class in the Thule faunal assemblages has a consistently higher proportion of caribou bones $(84 \%$ to $97 \%$ ) than is found in the Late Dorset assemblages. Second, in Thule Inuit contexts the proportion of specimens from adult caribou is greater, potentially indicating that Thule Inuit were able to hunt prime-aged individuals more selectively than their Late Dorset counterparts.

A second technological innovation that is critical for understanding these faunal differences relates to fishing. While both Dorset and Thule are assumed to have fished for Arctic char at stone weirs, Thule had a broader range of fishing technologies, including hooks and lines, lures, and multiple types of fish spear. These technologies appear to have resulted in the greater overall proportion of fish in the Thule faunal samples, which we believe to underrepresent the original numbers because of the presence of dogs. Thule also acquired a significantly higher frequency of lake trout within the fish sample, which was probably the result of their greater ability to fish in contexts other than at weirs during fish runs. In particular, the ability to jig with hooks through the ice of nearby Ferguson Lake may have led to greater fishing success for Inuit in the winter and thus provided an important backup resource to augment the supply of stored caribou and char. As mentioned above, however, it is also possible that the higher proportions of lake trout reflect the fact that Thule remained at the Bell site later into the winter than Late Dorset did. However, these two factors are likely related, since the ability to obtain fish from the lake during the winter would have been an incentive for Thule to remain in the area for a longer period during the winter than Late Dorset people, who lacked this type of fishing technology.

\section{CONCLUSION}

For Late Dorset and Thule archaeofaunas at the Bell site, similarities outweigh differences. Birds are always uncommon, fish are always relatively important, caribou always dominate the mammals, seals are always rare, and element distributions of the two most frequent species, caribou and char, are closely similar. These many similarities reflect the fact that Dorset and Thule, despite millennia of separate development and unique cultural and social organization, were operating under the same severe environmental constraints in virtually identical ecosystems. The differences that do exist, such as greater emphasis on secondary species (seal, fox, muskox, and various bird species) for Late Dorset and greater proportions of lake trout for Thule, can plausibly be linked to the more diverse and specialized technologies employed by Thule Inuit. Specifically, the bow and arrow and more diverse fishing technologies may have allowed Thule to concentrate their efforts to a greater degree on the focal resources at Iqaluktuuq - caribou and fish - while a lack of these technologies led Late Dorset to rely on a somewhat broader diet, as seen in the higher proportions of secondary resources. For Late Dorset, this trend is consistent with trends identified at sites throughout the High Arctic (Darwent, 2004).

However, the differences between the two societies' subsistence economies at Iqaluktuuq should not be overstated. Long-term success of the Late Dorset occupation at the Bell site is indicated by the deep, rich middens accumulated over several centuries and by the large and complex longhouse aggregation at the nearby Cadfael site (Friesen, 2009). In fact, this region may have seen a less pronounced difference between Dorset and Thule economies than occurred in many other Canadian Arctic and Greenland locations, where marine mammals dominated. In particular, in regions with access to significant numbers of bowhead whales, the presence of technologies such as umiaks and whaling gear, as well as the social structures required to hunt whales cooperatively, likely allowed Thule to acquire vast resource stores for consumption during the winter that were unavailable to Late Dorset (for further discussion of Late Dorset and Thule Inuit fauna, see Howse, 2016). Overall, there can be little doubt that the more diverse and specialized technologies Thule brought from Alaska were an important factor in their rapid displacement of Late Dorset; however, as shown by this study, in some regions the two societies were on a more nearly equal economic footing. 


\section{ACKNOWLEDGEMENTS}

We are both honoured to present this paper in a volume dedicated to the memory of Priscilla Renouf. She was an important role model, mentor, and source of encouragement for Lesley Howse and a highly valued colleague and source of scholarly inspiration for Max Friesen. Funding and logistical support for the fieldwork at Iqaluktuuq was received, with gratitude, from the Social Sciences and Humanities Research Council of Canada, the Government of Canada Program for the International Polar Year, the Polar Continental Shelf Project, and the Northern Scientific Training Program. The project was organized in cooperation with the Kitikmeot Heritage Society of Cambridge Bay, to whom Max Friesen expresses his thanks, as always.

\section{REFERENCES}

Banfield, A.W.F. 1974. The mammals of Canada. Toronto: University of Toronto Press.

Behrensmeyer, A.K. 1978. Taphonomic and ecologic information from bone weathering. Paleobiology 4(2):150-162.

Bielawski, E. 1979. Contactual transformation: The Dorset-Thule succession. In: McCartney, A.P., ed. Thule Eskimo culture: An anthropological retrospective. Mercury Series, Archaeological Survey of Canada Paper 88. Ottawa: National Museum of Man. 100-109.

Binford, L.R. 1981. Bones: Ancient men and modern myths. New York: Academic Press.

Butler, V.L., and Chatters, J.C. 1994. The role of bone density in structuring prehistoric salmon bone assemblages. Journal of Archaeological Science 21(3):413-424.

https://doi.org/10.1006/jasc.1994.1039

COSEWIC (Committee on the Status of Endangered Wildlife in Canada). 2004. COSEWIC assessment and update status report on the Peary caribou Rangifer tarandus pearyi and the barren-ground caribou Rangifer tarandus groenlandicus (Dolphin and Union population) in Canada. Ottawa, Ontario: COSEWIC.

Darwent, C.M. 2004. The highs and lows of High Arctic mammals: Temporal change and regional variability in Palaeoeskimo subsistence. In: Mondini, M., Muñoz, S., and Wickler, S., eds. Colonisation, migration and marginal areas: A zooarchaeological approach. London: Oxbow Books. 62-73.

Darwent, C.M., and Foin, J.C. 2010. Zooarchaeological analysis of a Late Dorset and an Early Thule dwelling at Cape Grinnell, Northwest Greenland. Geografisk Tidsskrift_-Danish Journal of Geography 110(2):315-336. https://doi.org/10.1080/00167223.2010.10669514

DFO (Department of Fisheries and Oceans). 2004. Cambridge Bay Arctic char. DFO Canadian Science Advisory Secretariat Stock Status Report 2004/010.

Dumond, M. 2006. Review of muskox status in the Kitikmeot region of Nunavut. Kugluktuk: Department of Environment, Government of Nunavut.
Friesen, T.M. 2000. The role of social factors in Dorset-Thule interaction. In: Appelt, M., Berglund, J., and Gulløv, H.C., eds. Identities and cultural contacts in the Arctic. Copenhagen: The Danish National Museum and Danish Polar Center. 206-220.

- 2002. Analogues at Iqaluktuuq: The social context of archaeological inference in Nunavut, Arctic Canada. World Archaeology 34(2):330-345.

https://doi.org/10.1080/0043824022000007134

— 2004. Contemporaneity of Dorset and Thule cultures in the North American Arctic: New radiocarbon dates from Victoria Island, Nunavut. Current Anthropology 45(5):685691. https://doi.org/10.1086/425635

- 2009. The last supper: Late Dorset economic change at Iqaluktuuq, Victoria Island. In: Maschner, H., Mason, O., and McGhee, R., eds. The Northern World AD 900-1400. Salt Lake City: The University of Utah Press. 235-248.

- 2013. The impact of weapon technology on caribou drive system variability in the prehistoric Canadian Arctic. Quaternary International 297:13-23.

Griebel, B. 2010. A conflict of interest: A case study for community archaeology in Nunavut, Canadian Arctic. Museum International 62(1-2):75-80. https://doi.org/10.1111/j.1468-0033.2010.01717.x

. 2013. Recharting the courses of history: Mapping concepts of community, archaeology, and Inuit Qaujimajatuqangit in the Canadian territory of Nunavut. PhD thesis, Department of Anthropology, University of Toronto, Toronto, Ontario.

Gunn, A., and Fournier, B. 1996. Skull and dental measurements from adult female caribou collected from Victoria Island and Pelly Bay, NWT, 1987-1990. Manuscript Report No. 85. Yellowknife: Department of Renewable Resources, Government of the Northwest Territories.

Howse, L. 2005. Faunal variability and the function of space within a Late Dorset house from Victoria Island, Nunavut. MA thesis, Department of Anthropology, University of Toronto, Toronto, Ontario.

2008. Late Dorset caribou hunters: Zooarchaeology of the Bell Site, Victoria Island. Arctic Anthropology 45(1):22-40. https://doi.org/10.1353/arc.0.0001

. 2016. Eating beyond ecology: The impacts of hunting technologies on archaeofaunas from the Eastern Arctic. PhD thesis, Department of Anthropology, University of Toronto, Toronto, Ontario.

Hufthammer, A.K. 1995. Age determination of reindeer (Rangifer tarandus L.). Archaeozoologia 7(2):33-41.

Jakimchuk, R.D., and Carruthers, D.R. 1980. Caribou and nuskoxen on Victoria Island, N.W.T. Yellowknife: Polar Gas Project.

Jingfors, K. 1984. Abundance, composition and distribution of muskoxen on southeastern Victoria Island. File Report No. 36. Yellowknife: N.W.T. Wildlife Service.

Kennett, D.J., Lambert, P.M., Johnson, J.R., and Culleton, B.J. 2013. Sociopolitical effects of bow and arrow technology in prehistoric coastal California. Evolutionary Anthropology: Issues, News, and Reviews 22(3):124-132. https://doi.org/10.1002/evan.21358 
Knuth, E. 1952. An outline of the archaeology of Peary Land. Arctic 5(1):17-33. https://doi.org/10.14430/arctic3897

Lam, Y.M., Chen, X., and Pearson, O.M. 1999. Intertaxonomic variability in patterns of bone density and the differential representation of bovid, cervid, and equid elements in the archaeological record. American Antiquity 64(2):343-362. https://doi.org/10.2307/2694283

Lyman, R.L. 2008. Quantitative paleozoology. Cambridge: Cambridge University Press. https://doi.org/10.1017/CBO9780511813863

Manning, T.H. 1960. The relationship of the Peary and barrenground caribou. Technical Paper No. 4. Montreal: Arctic Institute of North America.

Maxwell, M.S. 1985. Prehistory of the Eastern Arctic. Orlando: Academic Press.

McCartney, A.P., ed. 1979. Thule Eskimo culture: An anthropological retrospective. Ottawa: National Museum of Man Mercury Series, Archaeological Survey of Canada Paper 88.

McGhee, R. 1996. Ancient people of the Arctic. Vancouver: UBC Press.

- 2005. The last imaginary place: A human history of the Arctic world. Oxford: Oxford University Press.

Metcalfe, D., and Jones, K.T. 1988. A reconsideration of animal body-part utility indices. American Antiquity 53(3):486-504. https://doi.org/10.2307/281213

Miller, F.L.1974. Biology of the Kaminuriak Population of barrenground caribou, Part 2: Dentition as an indicator of age and sex; composition and socialization of the population. Canadian Wildlife Service Report Series No. 31.

Miller, G.H., Brigham-Grette, J., Alley, R.B., Anderson, L., Bauch, H.A., Douglas, M.S.V., Edwards, M.E., et al. 2010. Temperature and precipitation history of the Arctic. Quaternary Science Reviews 29(15-16):1679-1715. https://doi.org/10.1016/j.quascirev.2010.03.001

Morin, E. 2007. Fat composition and Nunamiut decision-making: A new look at the marrow and bone grease indices. Journal of Archaeological Science 34(1):69-82. https://doi.org/10.1016/j.jas.2006.03.015

Morrison, D.A. 1983. Thule culture in western Coronation Gulf, N.W.T. Mercury Series, Archaeological Survey of Canada Paper 116. Ottawa: National Museum of Man.

Morrow, J.E. 1980. The freshwater fishes of Alaska. Anchorage: Alaska Northwest Publishing Company.

Norman, L., and Friesen, T.M. 2010. Thule fishing revisited: The economic importance of fish at the Pembroke and Bell Sites, Victoria Island, Nunavut. Geografisk Tidsskrift - Danish Journal of Geography 110(2):261-278. https://doi.org/10.1080/00167223.2010.10669511
Park, R.W. 2010. Frozen coasts and the development of Inuit culture in the North American Arctic. In: Martini, I.P., and Chesworth, W., eds. Landscapes and societies. New York: Springer. 407-421. https://doi.org/10.1007/978-90-481-9413-1_25

Parmelee, D.F., Stephens, H.A., and Schmidt, R.H. 1967. The birds of southeastern Victoria Island and adjacent small islands. National Museum of Canada Bulletin No. 222, Biological Series No. 78. Ottawa: Queen's Printer.

Pielou, E.C. 1994. A naturalist's guide to the Arctic. Chicago: University of Chicago Press.

Porinchu, D.F., MacDonald, G.M., and Rolland, N. 2009. A 2000 year midge-based paleotemperature reconstruction from the Canadian Arctic archipelago. Journal of Paleolimnology 41(1):177-188. https://doi.org/10.1007/s10933-008-9263-x

Riddle, A.T.R. 2010. Camping at the caribou crossing: Relating Palaeo-Eskimo lithic technological change and human mobility patterns in southeastern Victoria Island, Nunavut. PhD thesis, Department of Anthropology, University of Toronto, Toronto, Ontario.

Riewe, R.R. 1992. Nunavut atlas. Edmonton: Canadian Circumpolar Institute and the Tungavik Federation of Nunavut.

Ryan, K. 2003. A Late Dorset semi-subterranean structure from the Bell Site (NiNg-2), Ekalluk River, Victoria Island. Etudes/ Inuit/Studies 27(1-2):91-110. https://doi.org/10.7202/010797ar

. 2012. The significance of choice in the Late Dorset: The technology of domestic architecture in the eastern North American Arctic c. 1500 B.P.-500 B.P. British Archaeological Reports, International Series No. 2444. Oxford: Archaeopress.

Sisk, M.L., and Shea, J.J. 2009. Experimental use and quantitative performance analysis of triangular flakes (Levallois points) used as arrowheads. Journal of Archaeological Science 36(9):2039-2047.

https://doi.org/10.1016/j.jas.2009.05.023

Storå, J. 2002. Neolithic seal exploitation on the Åland Islands in the Baltic Sea on the basis of epiphyseal fusion data and metric studies. International Journal of Osteoarchaeology 12(1):4964.

https://doi.org/10.1002/oa.612

Taylor, W.E., Jr. 1967. Summary of archaeological field work on Banks Island and Victoria Island, Arctic Canada, 1965. Arctic Anthropology 4(1):221-243.

___ 1972. An archaeological survey between Cape Parry and Cambridge Bay, N.W.T., Canada in 1963. Mercury Series, Archaeological Survey of Canada Paper 1. Ottawa: National Museum of Man.

Whitridge P.J. 2001. Zen fish: A consideration of the discordance between artifactual and zooarchaeological indicators of Thule Inuit fish use. Journal of Anthropological Archaeology 20(1):3-72.

https://doi.org/10.1006/jaar.2000.0368 